\title{
THE INFLUENCE OF A CROWN WALL ON WAVE OVERTOPPING OVER RUBBLE MOUND STRUCTURES
}

\author{
Koen Van Doorslaer, DEME nv and Ghent University, van.doorslaer.koen@deme-group.com \\ Andreas Kortenhaus, Ghent University, andreas.kortenhaus@ugent.be \\ Peter Troch, Ghent University, peter.troch@ugent.be \\ Goele De Meyere, Ghent University, goele.demeyere@ugent.be \\ Lieselot Vantomme, Ghent University, lieselot.vantomme@ugent.be
}

\section{MOTIVATION AND AIM}

The crest of a breakwater is often equipped with a crown wall with multiple functions such as a border of the pedestrian walkway, support of the rubble mound or concrete armour units, and reduction of the wave overtopping over the structure in storm conditions.

However, the knowledge on how a crown wall influences the overtopping discharge is yet still limited. EurOtop (2016) advises to take the maximum of the crest freeboard $R_{c}$ and the armour freeboard $A_{c}$ in case a crown wall is present, and to use the average between $A_{c}$ and $R_{c}$ when no crown wall is present. This advice is based on expert judgement rather than on experimental research. The goal of the present work is to carry out experimental research and confirm or update the advice on overtopping over a crown wall for rubble mound structures.

\section{MODEL SET UP}

Two test campaigns have been carried out in the two wave flumes of Ghent University: 1:20 model tests in a larger wave flume $(30 \mathrm{~m} \times 1 \mathrm{~m} \times 1.20 \mathrm{~m})$, and $1: 50$ model tests in a smaller wave flume $(15 \mathrm{~m} \times 0.35 \mathrm{~m} \times 0.60 \mathrm{~m})$.

A breakwater according to Figure 1 is built on scale in both flumes. The crown wall height $h_{\text {wall }}$ is varied (case 1: $A_{c}=R_{c}$ and $h_{\text {wall }}=0$, case 2: $A_{c}<R_{c}$ or $h_{\text {wall }}>0$ (situations $+W 1$ and $+W 2$ in Figure 1), case 3: $A_{c}>R_{c}$ or $\mathrm{h}_{\text {wall }}<0$ (situations $-\mathrm{W} 1$ and $-\mathrm{W} 2$ in Figure 1$)$ ). Also the crest width in front of the crown wall is varied $\left(G_{c}=1 P\right.$, $3 P, 5 P$ with $P=D_{n 50}$ ). The water level, the wave height and the wave period are also varied in the test matrix.

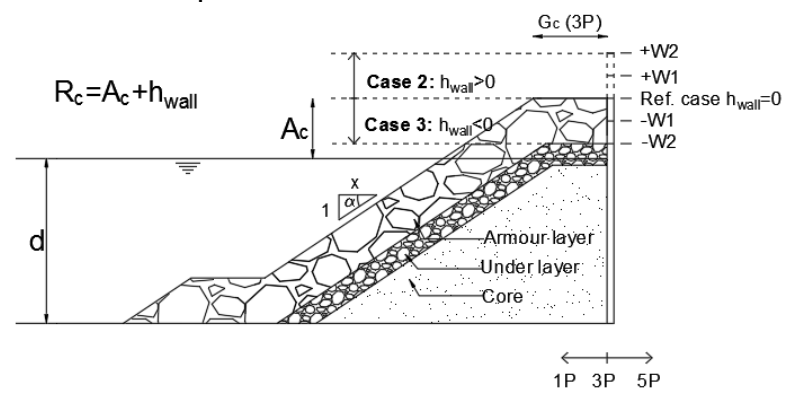

Figure 1. Rubble mound breakwater with varying crown wall height $\left(\mathrm{h}_{\text {wall }}=+\mathrm{W} 2,+\mathrm{W} 1,0,-\mathrm{W} 1,-\mathrm{W} 2\right)$ and varying distance from the armour slope $\left(\mathrm{G}_{\mathrm{c}}=1 \mathrm{P}, 3 \mathrm{P}, 5 \mathrm{P}\right)$

\section{ANALYSIS AND RESULTS}

First, tests on the reference situation, $A_{c}=R_{c}$ or $h_{\text {wall }}=0$, are carried out to determine the roughness factor $\gamma_{f}$ for the tests in both scales. By using this roughness factor $\gamma^{*}=\gamma_{\mathrm{f}}$ in EurOtop (2016)'s overtopping formula, Eq. (1), the tests are well predicted. See Figure 2.

$$
\frac{q}{\sqrt{g H_{m 0}^{3}}}=0.09 \exp \left[-\left(1.5 \frac{R_{C}}{H_{m 0} \gamma^{*}}\right)^{1.3}\right]
$$

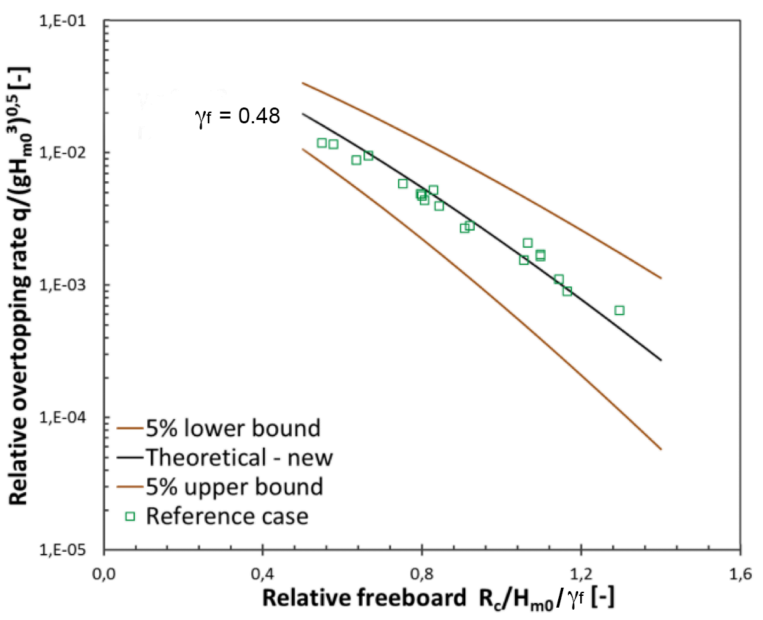

Figure 2. Overtopping results on the reference situation in the large wave flume. Dimensionless freeboard on the horizontal axis, with inclusion of the roughness factor $\gamma_{f}$, and dimensionless overtopping discharge on the vertical axis.

For the most common breakwater geometry, with a crown wall above the armour crest (case 2: $h_{\text {wall }}>0 \rightarrow$ $R_{c}>A_{c}$ ), test results show that EurOtop (2016)'s advice (use the maximum of $R_{c}$ and $A_{c}$ ) underestimates the measured overtopping discharge.

For case 3 with the wall below the rubble mound crest ( $h_{\text {wall }}<0 \rightarrow R_{c}<A_{c}$ ), using the maximum of both values $A_{c}$ and $R_{c}$ is underestimating the actual overtopping discharge. Using the average of $R_{c}$ and $A_{c}$ as suggested by EurOtop (2016) gives more promising results but slightly overestimates the results.

Besides the wall height, also a variation of the crest width and the wave period have a rather strong influence on the overtopping discharge: higher periods and/or shorter crests result into more overtopping. However, the advice in EurOtop (2016) does not take a variation of $\mathrm{G}_{\mathrm{c}}$ or $T_{p}$ into account for its reduction factor $\gamma^{*}$.

The research performed (326 tests) has resulted in a more consistent advice for all different variations. This lead to an influence factor to account for the wall height $\left(\gamma_{\mathrm{v}}\right)$, the crest width $\left(\gamma_{\text {crest }}\right)$ and the combined effect

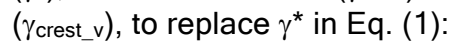

$$
\begin{aligned}
& \gamma_{v}=\exp \left(0.3131 \frac{h_{\text {wall }}}{R_{c}}\right) \\
& \gamma_{\text {crest }}=0.0695-0.274 \ln \left(\frac{G_{c}}{L_{m-1,0}}\right) \\
& \gamma_{\text {crest_v }}=\gamma_{v} \cdot \gamma_{\text {crest }}
\end{aligned}
$$


Eq. (2) to (4) have been derived for a parameter range as given in Table 1.

Table 1 Parameter range of the derived formulas (5) till (7)

\begin{tabular}{cccc}
\hline Parameters [-] & $\boldsymbol{\gamma}_{\mathbf{v}(5)}$ & $\boldsymbol{\gamma}_{\text {crest (6) }}$ & $\boldsymbol{\gamma}_{\text {crest_v (7) }}$ \\
\hline $\cot \alpha$ & 1.5 & 1.5 & 1.5 \\
$\xi_{\mathrm{m}-1,0}$ & $4.15-6.41$ & $3.02-7.74$ & $2.85-7.74$ \\
$\mathrm{~s}_{\mathrm{m}-1,0}$ & $0.011-$ & $0.007-0.049$ & $0.007-0.055$ \\
& 0.026 & & \\
$\mathrm{R}_{\mathrm{c}} / \mathrm{H}_{\mathrm{m} 0}$ & $0.30-1.841$ & $0.54-1.61$ & $0.30-2.00$ \\
$\mathrm{~h}_{\mathrm{wall}} / \mathrm{R}_{\mathrm{c}}$ & $-3.11-0.64$ & 0 & $-3.11-0.64$ \\
$\mathrm{G}_{\mathrm{c}} / \mathrm{L}_{\mathrm{m}-1,0}$ & $0.031-$ & $0.008-0.108$ & $0.007-0.122$ \\
& 0.034 & & \\
\hline
\end{tabular}

Figure 3 shows the final result after including the different influences from Eq. (2) to (4) in Eq. (1). Corrected results stay well within the $+/-5 \%$ boundary lines.

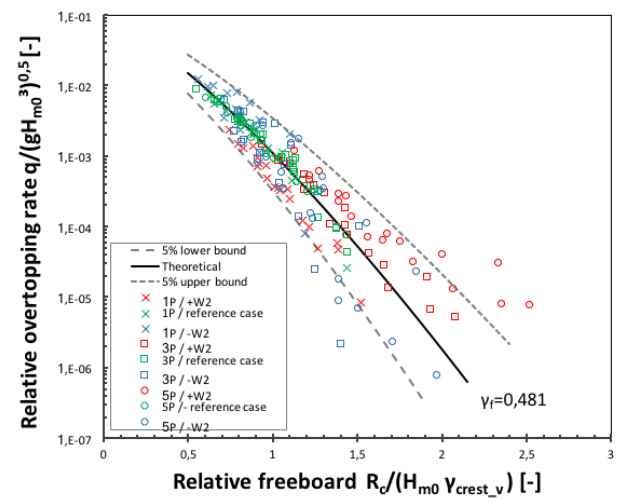

Figure 3. Complete dataset corrected by means of the new reduction factor $\gamma_{\text {crest } \_}$(which is a combination of the influence of the crest width and the crown wall height) found in this research.

The analysis of Eq. (2) to (4) will be explained in full detail in the presentation and the full paper.

\section{REFERENCES}

EurOtop, (2016). Manual on wave overtopping of sea defences and related Structures. An overtopping manual largely based on European research, but for worldwide application. Second Edition. Van der Meer, Allsop, Bruce, De Rouck, Kortenhaus, Pullen, Schüttrumpf,. Troch, Zanuttigh. www.overtopping-manual.com 